http://jmscr.igmpublication.org/home/ ISSN (e)-2347-176x ISSN (p) 2455-0450

crossref DOI: https://dx.doi.org/10.18535/jmscr/v8i7.39

Journal Of Medical Science And Clinical Research

\title{
Efficacy of Lingually Based Triangular Flap vs Routinely Used Triangular Flap Design in Third Molar Surgery
}

\author{
Authors \\ Dr Akash Prajapati ${ }^{1}$, Dr Shailesh Menat ${ }^{2}$, Dr Pravin Patel $^{3}$, Dr Nirav Patel ${ }^{4}$, \\ Dr Jigar Patel ${ }^{5}$ \\ ${ }^{1}$ Oral and Maxillofacial Surgeon, Private Practitioner at C.G Dental \& Maxface Clinic, Modasa, Gujarat \\ ${ }^{2}$ Oral and Maxillofacial Surgeon, Professor in OMFS Dept. at SankalchandPatel University, Visnagar, \\ Gujarat \\ ${ }^{3}$ Oral and Maxillofacial Surgeon, Private Practitioner at Himmatnagar, Gujarat \\ ${ }^{4}$ Oral and Maxillofacial Surgeon, Senior Lecturer in OMFS Dept. at Sankalchand Patel University, \\ Visnagar, Gujarat \\ ${ }^{5}$ Oral and Maxillofacial Surgeon, Senior Lecturer in OMFS Dept. at Sankalchand Patel University, \\ Visnagar, Gujarat
}

\begin{abstract}
To manage post-operative complications of surgical removal of lower third molar like pain, swelling, trismus impaired wound healing and periodontal defects is one of the most challenging tasks in current day in oral and maxillofacial surgical practice. Use of various flap design such as lingually based triangular flap may reduce complication that occur after surgical extraction of third molar. Efficacy of lingually based triangular flap vs routinely used triangular flap design in third molar surgery. The prospective randomized comparative study conducted on 30 patients undergone surgical removal of mandibular third molars. Group(A) 15 patients selected in the group where triangular flap was placed, Group (B) 15 patients selected in the group where lingual based triangular flap was placed. Swelling was evaluated using a modification of tape measure method described by Gabka and Matsumara, pain with a visual analogue scale (VAS), and trismus by measuring the maximum inter-incisal opening, pocket depth distal to second molar measuring by Williams prob. Assessments were made on the day of surgery and on post-operative days 2, 7, 14 and 21 after surgery. In group comparison, swelling showed statistically non-significant result in buccal based triangular flap vs lingual based triangular flap. While for pain no significance difference present in study except on 2 nd post-operative day. Trismus and pocket depth showed good result in lingual based triangular flap than buccal based triangular flap. The use of lingual based triangular flap in impacted third molar surgery reduce in pain, trismus and periodontal health. Hence, we recommended use of new flap design to minimize the post-operative discomfort after removal of mandibular third molar surgery.

Keywords: Triangular flap, Lingual based triangular flap, Swelling, Pain, Trismus, Periodontal Health, Third molar surgery.
\end{abstract}

\section{Introduction}

The mandibular third molars, or wisdom teeth, are present in $90 \%$ of the population, with $33 \%$ exhibiting at least one impacted third molar. Due to evolution and genetic variations, human jaw size is becoming smaller and third molar tooth is 
last to erupt so may not be room for it to emerge in the oral cavity. That's why high incidence rate of impacted third molars and so that their surgical excision is probably the most frequently performed operation in oral and maxillofacial surgery. ${ }^{1}$

In oral surgical procedures, it is advisable to place the mucoperiosteal incision on sound bone. Many flap designs used in impacted third molar surgery do not follow this rule, as they involve incisions that are placed on the extraction socket, so incidence rate if mucosal dehiscence is high, followed by secondary wound healing. The buccal flap is often tucked into the socket region and organization of the coagulum in the socket region may be disrupted, in secondary healing. In addition, the surgical area is left unprotected against oral pathogens and food residue. This condition leads to delayed wound healing and increases the risk of developing alveolar osteitis. Hence, existing wound dehiscence at the distofacial edge of the second molar probably extends the postsurgical treatment period. This may lead to an elevated level and duration of postoperative pain and discomfort. Furthermore, potential periodontal complications distal to the preceding second molar may also occur. Numerous investigators advocate using primary wound closure after mandibular third molar surgery to obtain quicker mucosal healing and superior amounts of bone regeneration. ${ }^{1}$

Incision lines should not lie over prospective bony defects or cut across major muscle or tendon insertions. They should be minimally extensive. The distal leg of the incisions usually made to access impacted mandibular third molars comes close to or even cuts across the insertion of the temporalis tendon and also lies over the bone error formed after removal of the tooth. This could be responsible, at least in part, for the occurrence of these complications like wound dehiscence, food lodgment and dry socket. This, therefore, is reason enough to consider alternative incision and flap designs. $^{2}$
Morbidities associated with the surgical removal of an impacted third molar such as pain, swelling, trismus, alveolar osteitis (dry socket), nerve damage and compromised periodontal status of the adjacent second molar; still pose a major problem for surgeons and patients. ${ }^{1}$

Many surgical approaches have been tried to minimize these complications, such as the use of surgical drains, different wound closure techniques, and various flap designs. ${ }^{1}$ Most commonly used flap designs are the envelope flap and triangular flap in impacted third molar surgery. In new flap design, incision lies over healthy bone and distal leg of incision lies away from insertion of temporalis tendon but in triangular based flap, distal leg of the incision lies near to insertion of temporalis tendon. The aim of this study was to compare a lingually based triangular flap design with the routinely used triangular flap design in the surgical removal of impacted mandibular third molars. ${ }^{1}$

\section{Material and Method}

The present prospective randomized comparative study was conducted on 30 patients undergone surgical removal of mandibular third molars in the Department of Oral \& Maxillofacial Surgery, Narsinhbhai Patel Dental College and Hospital, Visnagar, Gujarat, between January 2016 to October 2017 with ethical clearance. The study design was discussed with every selected patient and his / her written consent was taken prior to commencement of the study. Inclusion Criteria were following: A willingness to commit to a long-term follow up, Patients between 18-40 years of age group with good general health, Patients should have to sign the informed consent to carry out the intervention \& for inclusion in the study, Patient who have moderate and difficult score 5-7 and 7-10 (according to criteria and scores of Pederson scale) with position $\mathrm{B}$ or $\mathrm{C}$ impacted mandibular third molar, Patients should not have any allergies to medicines prescribed in postoperative period. Exclusion Criteria were following: An unwillingness to commit to a long- 
term follow up, Patients with localized infection or any pathology in the region of the 3rd molar, Patients with possible compromised immune status or systemic disease which might affect normal healing process. (e.g. anemia, deficiency disorder etc.) The patients with unacceptable oral habits, Patients allergic to local anesthetics or drugs, Patient with poor oral hygiene.

In this study randomly selected patients were divided into two groups (15 patients in each group). In GROUP A 15 patients selected in the group where triangular flap was used and in GROUP B 15 patients selected in the group where lingual based flap was used. As presurgical procedure guide we took Clinical case history record and clinical photographs, OPG radiograph will be taken pre-operatively, Examination and assessment of impacted third molar tooth and Blood investigations. (Hb, BT, CT)

Following the standard surgical protocol, under local anaesthesia the surgical removal of third molar procedure was carried out. The patient's face was prepared with betadine and the patient was draped in routine manner. Then the oral cavity and surrounding the tooth to be extracted was irrigated with diluted betadine by using the sterile syringe and needle under gentle pressure. Classical Inferior alveolar nerve block along with lingual and long buccal nerve block was administered using 2\% lignocaine hydrochloride (1:80000 adrenaline). GROUP A- An incision was made from the anterior border of the mandibular ramus to the distal surface of the distobuccal cusp of the mandibular second molar. It was extended through the sulcus to the distobuccal corner of the second molar crown. To alined with the mesiobuccal cusp of the second molar, the incision was continuous with a relieving vertical incision oblique into the mandibular vestibular fornix.

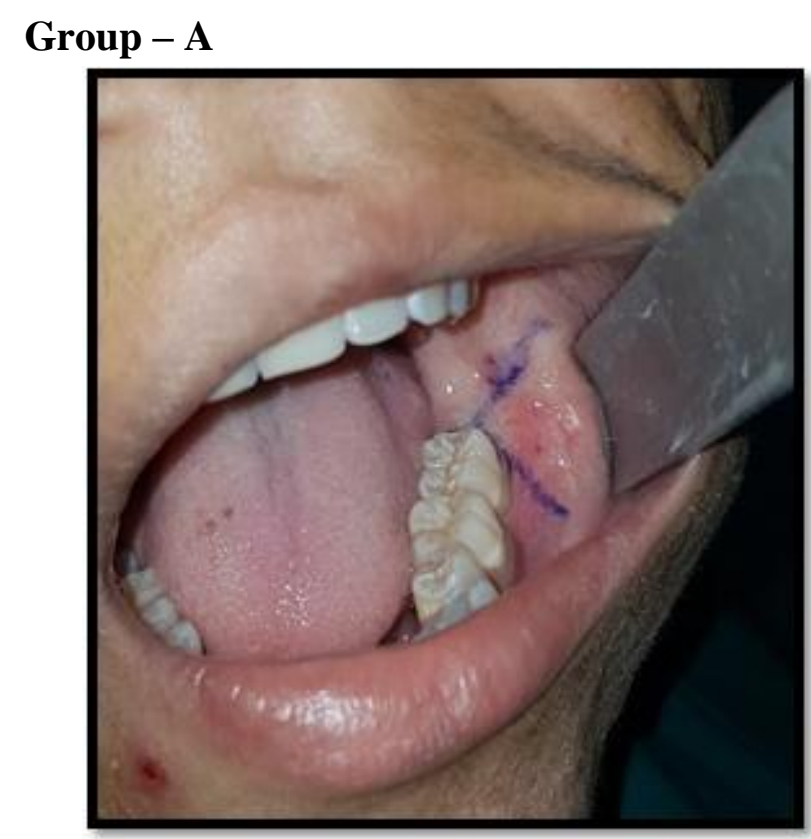

Incision marking

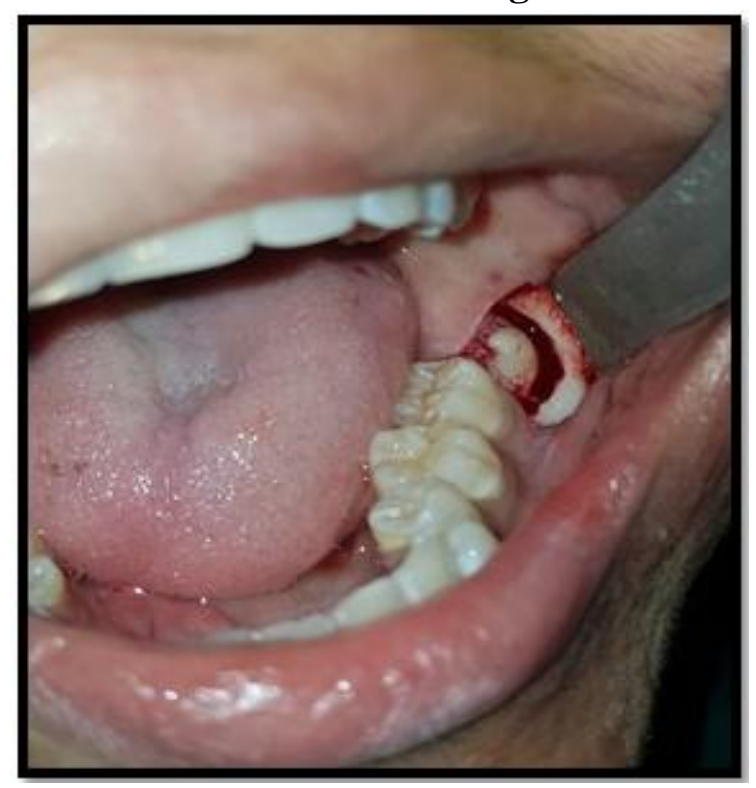

Tooth exposure

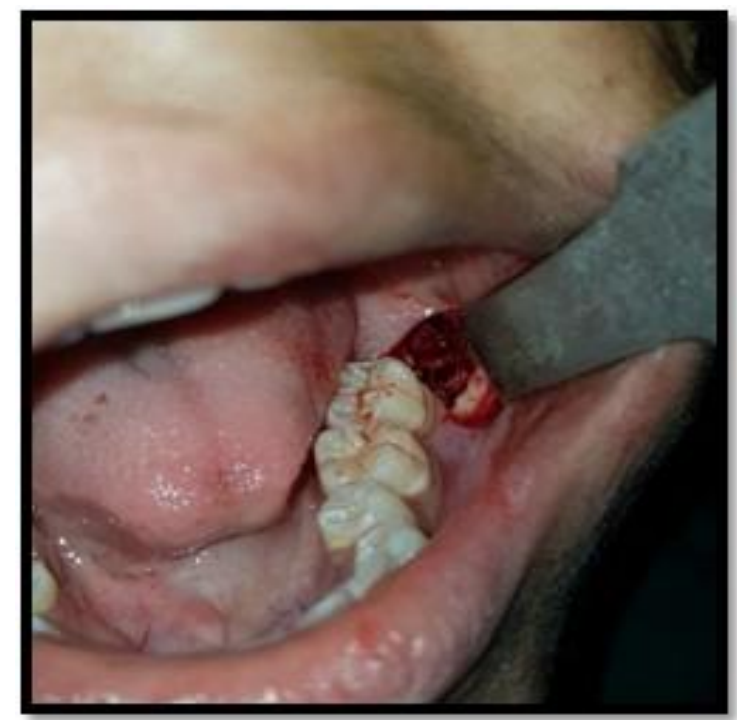

Extraction socket 
Group B- An incision was made adjacent to the distal surface of the mandibular second molar and extended along the sulcus to the distobuccal corner of the mandibular second molar. An oblique vestibular incision was made and extended into the vestibular fornix of the mandible aligned with the mesio-buccal cusp of the second molar. It was continued postero-superiorly towards the anterior border of mandibular ramus. The sharp end of a Howarth's periosteal elevator was inserted at the anterior end of incision and slide downwards along its edge into the sulcus to confirm that the scalpel has reached bone. The opposite blunt wide end was inserted beneath the periosteum to reflect the soft tissues at the correct plane of cleavage. Removal of bone was done with stainless steel burs 703(straight fissure bur) and no 8 (round bur). Buccal and distobuccal bone was removed and in some cases a notch was made in the cementoenamel junction of the impacted tooth for elevation. Constant irrigation with saline solution was done while removing the bone to prevent thermal necrosis. Sectioning of the tooth was done wherever it was indicated. Tooth was luxated with the help of straight elevator and surrounding bone was smoothened with bone file. The wound was irrigated with saline and checked for any bone / tooth particle etc. Removal of granulation tissue distal to 2nd molar was done. The irregular tissues were trimmed with scissors and interrupted sutures were given with 3-0 B.B silk. Pressure pack was given for half an hour. Following post-operative instructions were given: Keep the gauze piece in the mouth under pressure for $1 \mathrm{hr}$,, apply ice extra orally for $1 \mathrm{hr}$. (intermittently), Not to spit or gargle, avoid hot food and beverages, Take liquid diet, Do not touch the area with finger or tongue, The patient is instructed to follow the prescribed medication protocol postsurgically. i.e. Antibiotic [Amoxycillin $250 \mathrm{mg}$ a dicloxacillin 250mg 8 hourly for 5 days], Patients are instructed to take Analgesic in tablet form as and when necessary to control pain. [Diclofenac sodium $50 \mathrm{mg}$ ] Patients are also instructed to maintain record of the analgesic tablets consumed. Patients are followed up on 2 nd, 7 th, 14th and 21 st post-operative days and suture removal will be done on 7 th day.

\section{Group - B}

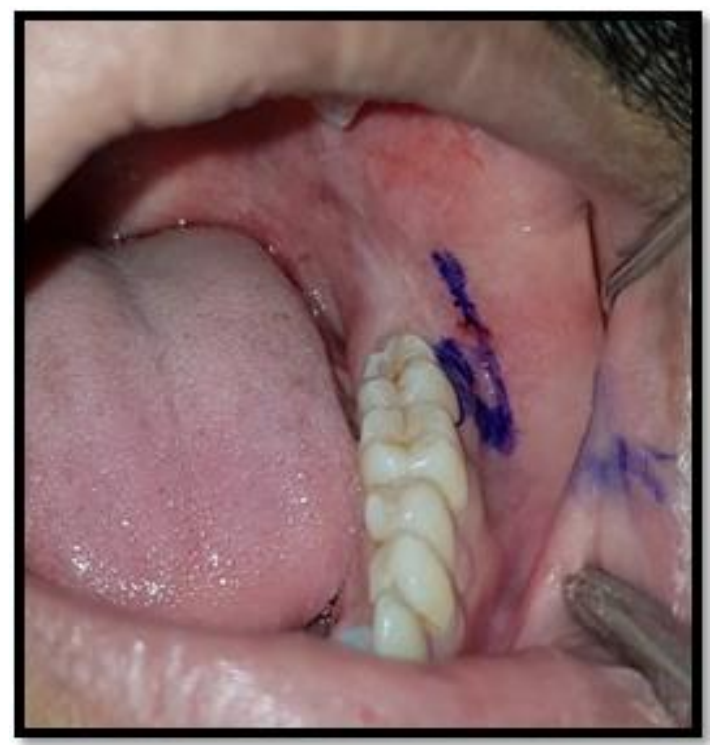

Incision marking

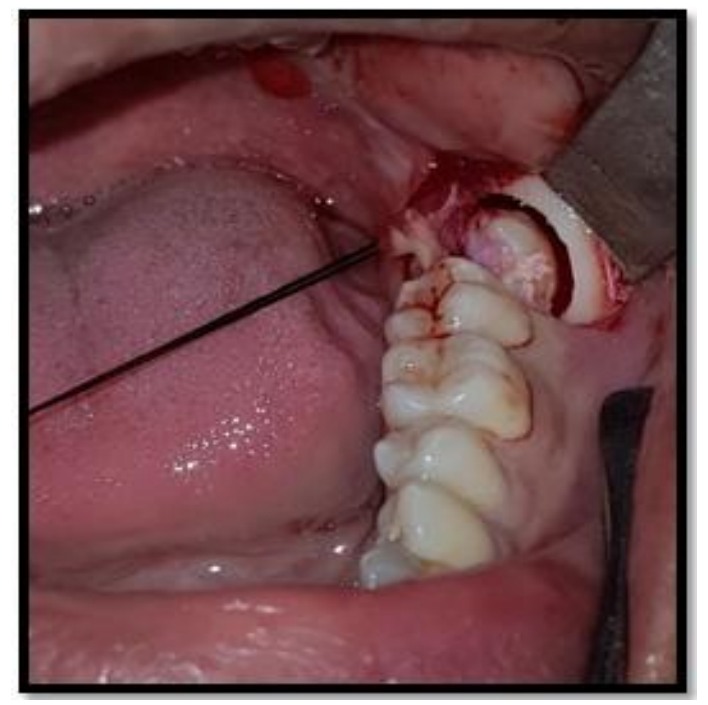

Tooth exposure

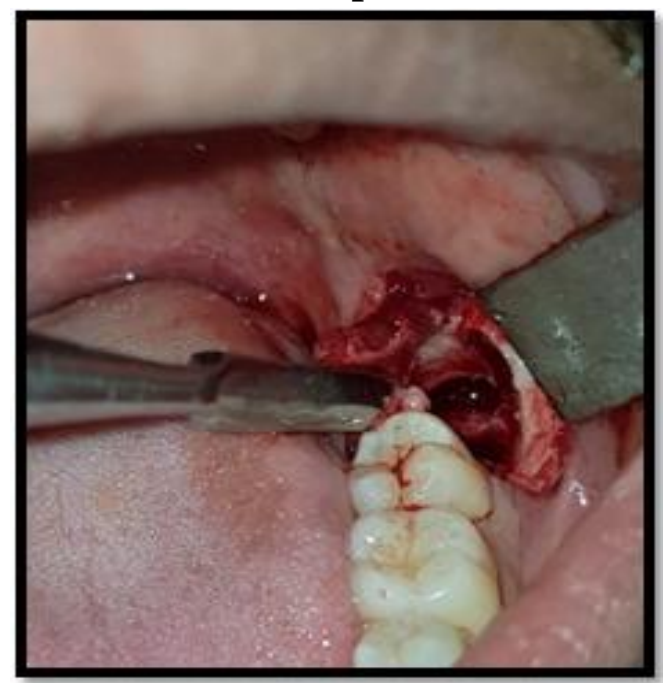

Extraction socket 
Clinical Criteria (Pain, Swelling, Trismus and Pocket depth) were following: Pain, Swelling, trismus and pocket depth were assessed at the $2 \mathrm{nd}$, 7th,14th and 21st day post-operatively, Pain intensity was assessed by using a 10-point Visual Analogue Scale (VAS), Severity of pain was evaluated on operation day and post-operative days 2, 7,14 and 21.The degree of facial swelling was determined by modification of the tape measure method described by Gabka and Matsumara. The three measurements were made between five reference points at interval of 2 nd, 7th, 14th, 21st day post-operatively. The distance between the lateral canthus of eye and angle of mandible. The distance between the tragus and soft tissue pogonion and the distance between tragus and out corner of mouth. (fig.16 \& 30) The mean of these three measurements were calculated. Trismus was evaluated by measuring the distance between the edges of the upper and lower right central incisors. Pre-operatively and on days 2, 7,14 and 21st. Pocket depth was evaluated by Williams probe distal to second molar on 2nd, 7th, 14th, 21st post operatively day.

\section{Result}

Total 30 patients were included in study who met our inclusion criteria. Group A (BUCCALY BASED TRIANGULAR FLAP) and Group B (LINGUALLY BASED TRIANGULAR FLAP). Mean age of patients in group A was $26.47 \pm 4.77$ years in which 7 ware males and 8 ware female subjects. Mean age of patients in group B was $22.53 \pm 3.46$ years in which 6 ware males and 9 ware female subjects. Mean time required for surgical procedure was more in group A (30.47 \pm 9.14 minutes $)$ than group B (25.13 \pm 4.01 minutes). Statistically, significant difference was present in time duration in surgical procedure between two groups.

\section{Distribution based on swelling score between two groups (Unpaired $t$ test)}

\begin{tabular}{|c|c|c|c|c|}
\hline Time & Groups & Mean(mm) & SD & P Value \\
\hline \multirow{2}{*}{ Pre-Operative } & Group A & 112.13 & 8.70 & \multirow{2}{*}{$0.429 \mathrm{NS}$} \\
\hline & Group B & 114.40 & 6.63 & \\
\hline \multirow[t]{2}{*}{2 Days } & Group A & 119.80 & 9.12 & \multirow{2}{*}{$0.947 \mathrm{NS}$} \\
\hline & Group B & 120.00 & 6.94 & \\
\hline \multirow{2}{*}{7 Days } & Group A & 117.13 & 9.11 & \multirow{2}{*}{$0.773 \mathrm{NS}$} \\
\hline & Group B & 118.00 & 7.08 & \\
\hline \multirow{2}{*}{14 Days } & Group A & 114.60 & 9.04 & \multirow{2}{*}{$0.586 \mathrm{NS}$} \\
\hline & Group B & 116.20 & 6.66 & \\
\hline 21 Days & Group A & 112.40 & 8.79 & $0.518 \mathrm{NS}$ \\
\hline
\end{tabular}

Statistically, no significant difference was present in swelling between both the groups at pre-operatively, 2 days, 7 days, 14 days and 21 days.

\section{Distribution based on pain score between two groups (Mann Whitney $U$ test)}

\begin{tabular}{|c|c|c|c|c|}
\hline Time & Groups & Mean & SD & P Value \\
\hline \multirow{2}{*}{ Pre-Operative } & Group A & 0.87 & 0.64 & \multirow{2}{*}{$0.653 \mathrm{NS}$} \\
\hline & Group B & 0.73 & 0.45 & \\
\hline \multirow[t]{2}{*}{2 Days } & Group A & 4.07 & 0.79 & \multirow{2}{*}{$0.023 \mathrm{~S}$} \\
\hline & Group B & 3.40 & 0.50 & \\
\hline \multirow{2}{*}{7 Days } & Group A & 2.53 & 0.99 & \multirow{2}{*}{$0.250 \mathrm{NS}$} \\
\hline & Group B & 2.07 & 0.59 & \\
\hline \multirow{2}{*}{14 Days } & Group A & 0.80 & 0.67 & \multirow{2}{*}{$0.137 \mathrm{NS}$} \\
\hline & Group B & 0.40 & 0.50 & \\
\hline \multirow{2}{*}{21 Days } & Group A & 0.00 & 0.00 & \multirow{2}{*}{$1.000 \mathrm{NS}$} \\
\hline & Group B & 0.00 & 0.00 & \\
\hline
\end{tabular}

Statistically, no significant difference was present in pain score between both the groups at pre-operatively, 7 days, 14 days and 21 days. Statistically, significant difference was present in pain score between both the groups at 2 days. 
Distribution based on mouth opening score between two groups (Unpaired $t$ test)

\begin{tabular}{|c|c|c|c|c|}
\hline Time & Groups & Mean(mm) & SD & P Value \\
\hline \multirow{2}{*}{ Pre-Operative } & Group A & 42.47 & 4.20 & \multirow{2}{*}{$0.131 \mathrm{NS}$} \\
\hline & Group B & 45.27 & 5.56 & \\
\hline \multirow[t]{2}{*}{2 Days } & Group A & 28.67 & 3.94 & \multirow{2}{*}{$0.027 \mathrm{~S}$} \\
\hline & Group B & 32.40 & 4.77 & \\
\hline \multirow{2}{*}{7 Days } & Group A & 32.93 & 3.63 & \multirow{2}{*}{$0.017 \mathrm{~S}$} \\
\hline & Group B & 36.73 & 4.54 & \\
\hline \multirow{2}{*}{14 Days } & Group A & 37.40 & 3.71 & \multirow{2}{*}{$0.023 \mathrm{~S}$} \\
\hline & Group B & 41.13 & 4.73 & \\
\hline \multirow{2}{*}{21 Days } & Group A & 41.73 & 4.09 & \multirow{2}{*}{$0.022 \mathrm{~S}$} \\
\hline & Group B & 45.27 & 3.97 & \\
\hline
\end{tabular}

Statistically, no significant difference was present in mouth opening between both the groups at preoperatively but significant difference was present in mouth opening between both the groups at 2 days, 7 days, 14 days and 21 days.

\section{Distribution based on pocket depth between two groups (Unpaired t test)}

\begin{tabular}{|c|c|c|c|c|}
\hline Time & Groups & Mean(mm) & SD & P Value \\
\hline \multirow{2}{*}{ Pre-Operative } & Group A & 2.73 & 0.45 & \multirow{2}{*}{$0.068 \mathrm{NS}$} \\
\hline & Group B & 2.33 & 0.48 & \\
\hline \multirow[t]{2}{*}{2 Days } & Group A & 7.53 & 0.74 & \multirow{2}{*}{$0.001 \mathrm{~S}$} \\
\hline & Group B & 6.33 & 0.97 & \\
\hline \multirow{2}{*}{7 Days } & Group A & 5.93 & 1.22 & \multirow{2}{*}{$0.004 \mathrm{~S}$} \\
\hline & Group B & 4.87 & 0.51 & \\
\hline \multirow{2}{*}{14 Days } & Group A & 4.33 & 1.44 & \multirow{2}{*}{$0.016 \mathrm{~S}$} \\
\hline & Group B & 3.27 & 0.70 & \\
\hline \multirow{2}{*}{21 Days } & Group A & 3.27 & 0.96 & \multirow{2}{*}{$0.005 \mathrm{~S}$} \\
\hline & Group B & 2.40 & 0.50 & \\
\hline
\end{tabular}

Statistically, no significant difference was present in pocket depth between both the groups at preoperatively but significant difference was present in pocket depth between both the groups at 2 days, 7 days, 14 days and 21 days.

\section{Discussion}

The surgical removal of lower third molar is one of the most common procedure performed in Oral and Maxillofacial surgery. It involves surgical trauma in a highly vascularized area, leading to expected inflammatory complications. The wound healing rate after the removal of a third molar is slower and the process of healing is more complicated than that after a routine tooth extraction. So, the complication rates after surgical removal is much higher than normal tooth extraction. Surgical removal of third molars are usually associated with various complication like pain, swelling and trismus in initial post-operative period which all may lead to severe patient discomfort and hampers patient day to day life.

In this study, the post-operative outcomes of an alternative flap design, the lingually based triangular flap, were compared to those following the use of the traditional buccally based triangular flap. To standardize the surgical protocol and to decrease the effects of variables on the final outcomes, all surgeries were performed by a single surgeon under similar clinical conditions. Furthermore, patients were selected from a similar age group, with each patient serving as their own control. Thus, the flap design was the sole independent factor associated with the severity of postoperative morbidities; it was attempted to eliminate the patient compliance factor, and all other possible factors were kept as homogeneous as possible. 1

With the exception of a few flap designs, it appears that the incisions of many conventional flap designs are not placed on healthy bone. With the comma shaped flap described by Nageshwar,2 the tongue-shaped flap designed by Berwick 8 and the lingually based triangular flap used in the 
present study, the incisions are not placed on the bony defect formed from the extraction of the impacted molar. Nageshwar 2 compared the standard modified envelope flap with comma shaped flap designs and found that pain scores were significantly lower when the comma-shaped flap design technique was used.2 Also, it was found that the incidence of swelling and trismus was lower in the comma-shaped flap group, but this was not statistically significant. Kumar et al.4 evaluated the effect of a comma-shaped flap design and standard flap design (Ward's incision) on pain, swelling, and trismus after impacted third molar surgery.

In new flap (lingually based triangular flap), incision is not placed on prospective bony defects so less possibilities for food lodgment therefore less chances for wound dehiscence. We observed that the lingual based flap was associated with lesser pocket depth and a lower incidence of trismus. A surgical trauma in the oral cavity always cause tissue injury characterized by hyperemia, vasodilation, increase capillary permeability with liquid accumulation in the intestinal space and granulocytes and monocytes migration, due to the increase osmotic pressure in capillaries.

Post-operative facial swelling is common after surgical removal of third molars, and according to D. Glenn Kirk17 et al used two different flap designs will produce postoperative swelling and a degree of extraoral asymmetry and this increased swelling was not associated with any difference in trismus, initial pain severity, or recovery over the postoperative period monitored. In our study, we used triangular flap and lingual based triangular flap, there was not marked difference in swelling between 2nd day,7th day, 14th day and 21st day. On 2nd post-op day of both incisions show marked increase level of swelling. By next follow up days swelling level reduced.

Trismus is an inability to open the mouth. Dorland define trismus as a motor disturbance of the trigeminal nerve, especially spasm of the masticatory muscles, with difficulty in opening the mouth. Most surgical procedures result in a certain amount of edema or swelling leading to trismus. Trismus is also partially associated to postoperative pain and is more intense on the first day after surgery with a mean reduction in oral aperture. Trismus (mouth opening) was evaluated by measuring the distance between the edges of the upper and lower right central incisors on preop, 2nd, 7th, 14th and 21st post op day. Maximum inter incisal distance (MID) used as the index of trismus.

In present study, post-operative mouth opening was better in lingual based triangular flap than buccal based because in the buccal based triangular flap distal leg of the incisions conventionally made to access impacted mandibular third molars comes close to or even cuts across the insertion of the temporalis tendon so post-operative trismus occur commonly. This result shows significance difference in trismus on 2nd, 7th, 14th and 21st post-operative day. The result of present study is in accordance with $U$. Yolcu1.

Surgical procedures are always associated with pain. Pain is not generated due to incision itself (whatever type of incision) but due to release of endogenous mediator such as bradykinin, serotonin and certain type of prostaglandin. Depending upon procedure pain may range from mild to severe It is broadly accepted that subjective methods of determining the pain experience are the most valid. Visual analogue scale (VAS) is subjective method of measuring pain. It is very simple, reliable means of allowing patients to express their feelings with high degree of resolution, without resorting to cumbersome questionnaires.

According to Lucia Lago Mendez et al11, investigate the influence of surgical difficulty on postoperative pain after extraction of mandibular third molars and concluded that more severe pain on the first day and pain subsequently declined steadily until postoperative day 7 , when the sutures were removed. In present study we have recorded pain at interval of pre-op, 2nd day, 7th 
day, 14th day and 21st day post-operatively by VAS in both the groups. In group comparison of pain, we found not difference on 7th, 14th and 21 st day post-operatively except on 2 nd postoperative day.

Regarding to periodontal health of adjacent molar, Peng et al12 demonstrate that mandibular third molar surgery may compromise periodontal health on distal surface of second molar. Results of several studies have shown that flap design has no connection with periodontal health status of the mandibular second molar after the extraction of adjacent impacted third molar but different short and long-term results of these correlations have been reported34. They conclude that mean probing depth at distal and buccal sites was significantly different between the flaps at pre-op, 2nd day, 7th day, 14th day and 21st post op day ( $\mathrm{p}>0.05)$.

Jordan L. Silva et al6 stated that probing depth loss is usually located at the distal surface of the gingival margin adjacent to the second molar, where the relieving incision is done followed by intrasulcular incision. They did comparisons of the vertical flap design and the L-shaped flap design with relieving incisions showed that both caused no periodontal complications to the adjacent second molars.

In buccal based triangular flap, the closure is on bony defect so chances of food lodgment, alveolar ostitis and wound dehiscence. Existing surgical wound infection at the distofacial edge of the second molar probably extends the postsurgical treatment period. This may lead to an elevated level and duration of postoperative pain, discomfort and potential periodontal complications distal to the preceding second molar may also occur.

The result of our study demonstrates significance difference between buccal based triangular flap and lingual based flap in pocket depth. On 2nd day, 7th day, 14th and 21st post-operative day there was significance difference in both flaps. Lingual based flap shows less pocket depth than buccally base triangular flap.
So, the results of present study showed both buccal based and lingual based triangular flap have complications like swelling, pain, pocket depth and trismus after surgical removal of mandibular third molar tooth. By comparing efficacy of both flap we found no statistically difference in swelling and pain but lingual based flap has better efficacy in trismus and pocket depth than buccal based flap.

\section{Conclusion}

The present clinical study was attempt to compare swelling, pain and trismus, probing depth distal to second molar between study group A (buccal based triangular flap) and group B (lingual based triangular flap) after surgical removal of third molar. We conclude that both flaps have equal effect on swelling on post-operative, $2^{\text {nd }}, 7^{\text {th }}, 14^{\text {th }}$ and $21^{\text {st }}$ day. For pain there was significant difference on only 2 nd post-operative day. There was statistically difference in trismus and probing depth distal to second molar in third molar surgery on 2 nd and 7th, 14th and 21st post-operative day. From literature reviewed it was concluded that different type of flap designs appeared to have on effect on post-operative pain, swelling, trismus and periodontal health following surgical removal of impacted mandibular third molar. From the study we conclude that new flap (lingual based triangular flap) is effective in all parameters except swelling than buccally based triangular flap.

\section{References}

1. U*. Yolcu, A.H. Acar. Comparison of a new flap design with the routinely used triangular flap design in third molar surgery. Int. J. Oral Maxillofac. Surg. 2015;

2. Nageshwar. Comma incision for impacted mandibular third molars. J Oral Maxillofac Surg 2002; 60:1506-9.

3. Baqain ZH, Al-Shafii A, Hamdan AA, Sawair FA. Flap design and mandibular third molar surgery: a split mouth 
randomized clinical study. Int $\mathrm{J}$ Oral Maxillofac Surg 2012; 41:1020-4.

4. Kumar BS, Sarumathi T, Veerabahu M, Raman U. To compare standard incision and comma shaped incision and its influence on post-operative complications in surgical removal of impacted third molars. J Clin Diagn Res 2013; 7:1514-8.

5. Sanchis Bielsa JM, Herna'ndez-Baza'n S, Pen arrocha Diago M. Flap repositioning versus conventional suturing in third molar surgery. Med Oral Patol Oral Cir Bucal 2008; 1:138-42.

6. Silva JL, Jardim EC, dos Santos PL, Pereira FP, Garcia Junior IR, Poi WR. Comparative analysis of 2-flap designs for extraction of mandibular third molar. $\mathbf{J}$ Craniofac Surg 2011; 22:1003-7.

7. Babatunde Olamide Bamgbose, Jelili Adisa Akinwande2, Wasiu Lanre Adeyemo1. Effects of co-administered dexamethasone and diclofenac potassium on pain, swelling and trismus following third molar surgery. Head \& Face Medicine 2005, 1:11 doi:10.1186/1746160X-1-11.

8. Berwick WA. Alternate method of flap reflection. Br Dent J 1966; 21:295-6.

9. Thiago de Santana-Santos, Jadson-AlípioSantana de Souza-Santos. Prediction of postoperative facial swelling, pain and trismus following third molar surgery based on preoperative variables. Med Oral Patol Oral Cir Bucal. 2013 Jan 1;18 (1): e65-70.

10. Seyed Ahmad Arta, Reza Pourabbas Kheyradin, Ali Hossein Mesgarzadeh, Bahador Hassanbaglu. Comparison of the Influence of Two Flap Designs on Periodontal Healing after Surgical Extraction of Impacted Third Molars. J Dent Res Dent Clin Dent Prospects 2011; 5(1):1-4

11. Lucía Lago-Méndez, MárcioDiniz-Freitas, Carmen Senra-Rivera, Francisco Gude-
Sampedro, José Manuel Gándara Rey, and Abel GarcíaGarcía. Relationships Between Surgical Difficulty and Postoperative Pain in Lower Third Molar Extractions. American Association of Oral and Maxillofacial Surgeons J Oral Maxillofac Surg 65:979-983, 2007.

12. Peng KY, Tseng YC, Shen EC, Chiu SC, $\mathrm{Fu}$ E, Huang YW. Mandibular second molar periodontal status after third molar extractions. J Periodontol 2001; 72:16471651.

13. Yakup U“" stu“n, Comparison of the effects of 2 doses of methylprednisolone on pain, swelling, and trismus after third molar surgery. Oral Surg Oral Med Oral Pathol Oral RadiolEndod 2003; 96:535-9.

14. Kamran Bokhari Syed, Falah Hassan Khuzayyim Al Qahtani, Abdul Hakeem Ayed Mohammad, Ismail Mohammad Abdullah, Hussain Saad Hussain Qahtani, Mohammad Shahul Hameed. Assessment of Pain, Swelling and Trismus Following Impacted Third Molar Surgery Using Injection Dexamethasone Submucosally: A Prospective, Randomized, Crossover Clinical Study. J Int Oral Health 2017; 9:116-21.

15. JOSÉ RODRIGUES LAUREANO FILHO, EMANUEL DIAS de OLIVEIRA e SILVA, IGOR BATISTA CAMARGO, FABIANA M. V.GOUVEIA. The influence of cryotherapy on reduction of swelling, pain and trismus after thirdmolar extraction. JADA, Vol. 136.

16. T. H. Al-Khateeb, Y. Nusair, Effect of the proteolytic enzyme serrapeptase on swelling, pain and trismus after surgical extraction of mandibular third molars. Int. J. Oral Maxillofac. Surg. 2008; 37: 264268.

17. D. Glenn Kirk, Peter N. Liston, Darryl C. Tong, Robert M. Love. Influence of two different flap designs on incidence of pain, swelling, trismus, and alveolar osteitis in 
the week following third molar surgery. Oral Surg Oral Med Oral Pathol Oral Radiol Endod 2007;104: e1-e6.

18. Hidemichi Yuasaa, b, Masayuki Sugiurac. Clinical postoperative findings after removal of impacted mandibular third molars: prediction of postoperative facial swelling and pain based on preoperative variables. British Journal of Oral and Maxillofacial Surgery (2004) 42, 209214.

19. Janne Tiigimae-Saar, Edvitar Leibur, TiiaTamme. The effect of prednisolone on reduction of complaints after impacted third molar removal. Stomatologija, Baltic Dental and Maxillofacial Journal, 12: 1722, 2010.

20. Abel garciagarcia, Trismus and Pain After Removal of Impacted Lower Third Molars. J Oral Maxillofac Surg 55:12231226, 1997.

21. Jodie Barden, Jayne E. Edwards, Henry J. McQuay, R. Andrew Moore. Pain and analgesic response after third molar extraction and other postsurgical pain. Pain 107 (2004) 86-90.

22. Gary D. Slade, Susan P. Foy, Daniel A. Shugars, Ceib Phillips, Raymond P. White Jr. The Impact of Third Molar Symptoms, Pain, and Swelling on Oral Health-Related Quality of Life. American Association of Oral and Maxillofacial Surgeons J Oral Maxillofac Surg 62:1118-1124, 2004.

23. C.s.holland, o. iindle,t.d.,b.d. The influence of closure or dressing of third molar sockets on post-operative swelling and pain. British Journal of Oral and Maxillofacial Surgery (1984) 22, 65-71.

24. R. A. Seymour, p. J. Kelly, j. E. Hawkesford, The efficacy of ketoprofen and paracetamol (acetaminophen) in postoperative pain after third molar surgery. Br J Clin Pharmacol 1996; 41: 581-585.
25. Christian Freudlsperger, Timo Deiss, Jens Bodem, Michael Engel, Juergen Hoffmann. Influence of Lower Third Molar Anatomic Position on Postoperative Inflammatory Complications. American Association of Oral and Maxillofacial Surgeons J Oral Maxillofac Surg 70:12801285, 2012. 